\title{
Tumor Growth Attenuating Effects of Naringenin
}

\author{
Shailendra Kapoor
}

Received: 26 December 2012 / Accepted: 2 October 2013 /Published online: 6 December 2013

(C) Arányi Lajos Foundation 2013

To the Editor:

Sulfikkarali et al. have provided interesting data in their recent article [1]. Naringenin may attenuate tumor growth in a number of other systemic malignancies.

For instance, attenuation of tumor growth is seen in gliomas. It mediates this effect by attenuating cyclooxygenase- 2 expression within the cancerous cells [2]. As a result lipid peroxidation is markedly inhibited. Naringenin also alters the $\mathrm{Bcl}-2 / \mathrm{Bax}$ ratio. PI3K activity is also decreased at the same time. Simultaneous inhibition of protein kinase $\mathrm{B}$ and protein kinase $\mathrm{C}$ accompanies the above changes [3]. Up- regulation of $\mathrm{Cx} 43$ is seen. NF-kB activity is also decreased markedly [4]. These changes result in marked attenuation of intra- tumoral proliferation and accentuation of apoptosis within the gliomas. The release of cytochrome $\mathrm{C}$ from the mitochondria is further augmented.

Naringenin also decreases tumor growth in gastrointestinal carcinomas. For instance, in gastric carcinomas it mediates this role by augmenting the redox activity in the tumor cells [5]. Naringenin also attenuates the activity as well as levels of intra- tumoral fucose, sialic acid and hexose [6]. Attenuation of these glycoproteins further mitigates tumor growth in gastric carcinomas. Similar effects are seen in hepato- cellular carcinomas. It decreases NF- $\mathrm{KB}$ activity within the tumor cells. Naringenin administration up- regulates Bax while down- regulating Bcl-2 [7]. Similar inhibitory effects on VEGF activity are seen. MMP-2 and MMP-9 downregulation accompanies the above changes. PCNA expression is also decreased resulting in augmented apoptosis and inhibition of proliferation.

The above examples clearly illustrate the significant antineoplastic effects of naringenin and reaffirm the need for further studies to fully evaluate these effects.

\section{References}

1. Sulfikkarali N, Krishnakumar N, Manoharan S, Nirmal RM (2012) Chemopreventive efficacy of naringenin-loaded nanoparticles in 7,12dimethylbenz(a)anthracene induced experimental oral carcinogenesis. Pathol Oncol Res 19:287-296

2. Sabarinathan D, Vanisree AJ (2012) Plausible role of naringenin against cerebrally implanted C6 glioma cells in rats. Mol Cell Biochem 375:171-178

3. Sabarinathan D, Mahalakshmi P, Vanisree AJ (2011) Naringenin, a flavanone inhibits the proliferation of cerebrally implanted C6 glioma cells in rats. Chem Biol Interact 189:26-36

4. Sabarinathan D, Mahalakshmi P, Vanisree AJ (2010) Naringenin promote apoptosis in cerebrally implanted C6 glioma cells. Mol Cell Biochem 345:215-222

5. Ekambaram G, Rajendran P, Magesh V, Sakthisekaran D (2008) Naringenin reduces tumor size and weight lost in N-methyl-N'-nitro$\mathrm{N}$-nitrosoguanidine-induced gastric carcinogenesis in rats. Nutr Res 28:106-112

6. Ekambaram G, Rajendran P, Devaraja R, Muthuvel R, Sakthisekaran $\mathrm{D}$ (2008) Impact of naringenin on glycoprotein levels in N-methyl-N'nitro-N-nitrosoguanidine-induced gastric carcinogenesis in rats. Anticancer Drugs 19:885-890

7. Subramanian P, Arul D (2012) Attenuation of NDEA-induced hepatocarcinogenesis by naringenin in rats. Cell Biochem Funct 31 : $511-517$

S. Kapoor $(\bowtie)$

Chicago, IL, USA

e-mail: shailendrakapoor@yahoo.com 